\title{
Postural Adjustment to the Line of Center of Gravity
}

\author{
Kenichi Takahashi ${ }^{1)}$, Masaru Suda ${ }^{1)}$, Mariko Usuba ${ }^{1)}$, Yoshiaki Wasai ${ }^{1)}$, \\ Hiroshi TSUKAYAMA ${ }^{2)}$ \\ ${ }^{1)}$ Department of Physical Therapy, Tsukuba Technical College, Tsukuba 305, Japan \\ ${ }^{2)}$ Tsukuba Technical College Affiliated Clinic, Tsukuba Technical College
}

J. Phys. Ther. Sci.

7: 65-69, 1995

\begin{abstract}
The flexibility of posture was examined by adjusting one body part to the line of the center of gravity (LCG). Fifteen healthy subjects participated in the experiment and their LCGs were determined with a force plate. The difference between the body part and LCG as recorded by a videocamera before adjustment was compared with that after adjustment. The results obtained were 1) the center of gravity was positioned more anteriorly than is generally believed to be the case, 2) the position of the head was before LCG, and both the shoulder and the knee were behind it, 3) the knee was stable at adjusting one of the other parts of body, and the shifting length of the head and hip were related to the adjusting length of these lower parts, i.e. the head was related to the shoulder and the hip was to the knee. We discussed the young people's posture, and the stability of the knee to body alignment. In physical training aimed at adjusting posture, it was suggested that the alignment of lower extremities, especially the hip, must be controlled.
\end{abstract}

Key words: Posture, Force plate, Center of gravity, Rehabilitation.

(This article was submitted Sept. 30, 1995, and was accepted Nov. 20, 1995)

\section{INTRODUCTION}

What is the definition of good posture? Brunnstrom $^{1)}$ states that it is a condition with the minimum consumption of energy. But we cannot define good posture in these terms alone. For example, the postures of old men are no good even if they stand in a relaxed state without extra muscle activity $^{2-3)}$. Nakamura ${ }^{4}$ explains that posture needs to satisfy not only energic but also, medical, aesthetic and other factors. Posture can be said to be at its best when the line of the center of the gravity passes through the external acoustic meatus, acromion and greater trochanter, and passes in front of the knee joint and $2 \mathrm{~cm}$ ahead of the lateral malleolus.

Body alignment during stance is established by musculo-skeletal structures. The parts of the structure interact with each other throughout life. How can we correct misplaced aligment. This question is a very important one for physical therapy.

The purpose of this study is to investigate what extent of flexibility the body has and to offer some basic data for use in physical therapy.

\section{METHODS}

\section{Subjects}

Experiments were carried out on fifteen healthy subjects (male 9, female 6) aged 19-48 years, with a mean age $29 \pm 9$ years, a mean body weight 59.9 $\pm 9.9 \mathrm{~kg}$ and a mean height $165.0 \pm 7.6 \mathrm{~cm}$, all of whom gave informed consent.

\section{Apparatus and procedure}

The experimental arrangement is shown in Fig. 1. The subjects were asked to stand at ease on a force plate (Anima, Twin Gravicoder G6100) (A in Fig. 1) and to watch a monitoring television (D) 
(Sony, Trinitron color TV, KV-29HR1) placed at eyesight level.

Markers with a black circle of $2 \mathrm{~mm}$ diameter in center were attached to some body parts. The line of the center of gravity (LCG) was, in general, regarded to pass through them when posture was reasonable. The positions of the markers were as follows: extenal acoustic meatus (head), acromion (shoulder), greater trochanter (hip), center of knee joint (knee) and top of lateral malleolus (ankle), which could be monitored by TV at height of their eyes. These markers were taken by a videocamera (E) set at $2 \mathrm{~m}$ from the left side of force plate. LCG was established as follows. At first, the position of center of gravity was decided with a force plate. Then, the centers of 3 steel wires which

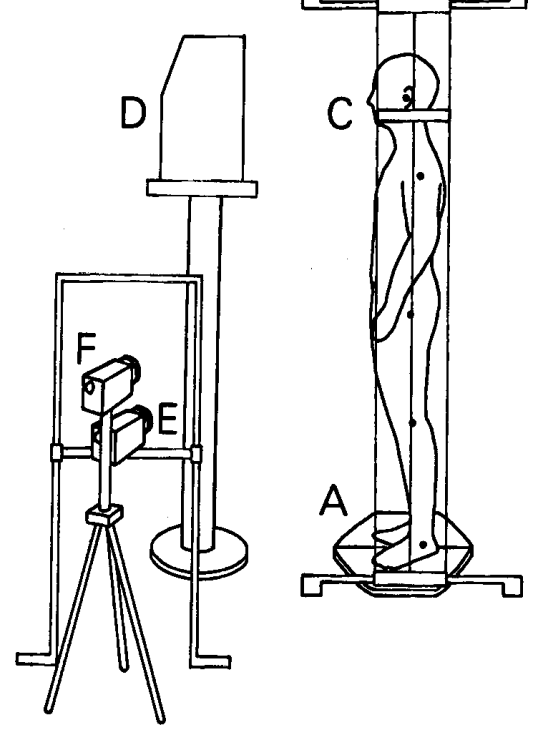

Fig. 1. Experimental arrangement used for studying postural adjustment. connected to two ajustable bars (B) were fitted in the position of the CG. The center wire is then equal to LCG in lateral view.

A scale (C) which could be moved vertically and positioned at each marker's height was attached to the wires horizontally. The difference from each marker to LCG could be read by the scale. The data were recorded on $8 \mathrm{~mm}$ videocamera $(\mathrm{F})$ (Sony, Video-Hi8 Handycam) which was set behind the monitor's. Both cameras were vertically placed to set one of the markers in the center of TV screen.

Eleven of 15 subjects also participated in a postural adjustment experiment. The standing posture of the subjects were recorded, and they were then asked to adjust each marker to LCG as they watched TV. The differences between a marker and LCG were recorded by a videocamera $(\mathrm{F})$.

\section{Analysis}

The difference from each marker to LCG was read with experimenter's eye and 10 samples obtained were averaged during 20 seconds. The unit of length was millimeter. Student's t test and ANOVA was used to determine significant differences.

\section{RESULTS}

The mean difference from markers to LCG in all subjects when they stood naturally at ease was shown in Table 1. Plus means that the marker is before the LCG and minus means behind. In avevage cases, the head was positioned before the LCG. For maintaining the balance of weight in the LCG, the shoulder, knee and ankle were positioned behind the LCG. Hip (Greater trochanter) was on the line. Based on our observations, the subjects

Table 1. The mean difference between body markers and the line of the center of gravity (LCG)

\begin{tabular}{cccccc}
\hline & $\begin{array}{c}\text { Ext. acoustic } \\
\text { meatus }\end{array}$ & Acromion & $\begin{array}{c}\text { Greater } \\
\text { trochanter }\end{array}$ & $\begin{array}{c}\text { Knee } \\
\text { joint }\end{array}$ & $\begin{array}{c}\text { Lat. } \\
\text { malleolus }\end{array}$ \\
\hline $\begin{array}{c}\text { Average } \\
\text { SD }\end{array}$ & $*$ & $*$ & & $*$ & $*$ \\
\hline
\end{tabular}

Plus means that the marker is before LCG and minus means behind it.

* indicates a significant difference of marker to LCG in Student's t test $(\mathrm{P}<0.001)$.

The unit of length is millimeter. $\mathrm{n}=15$. 


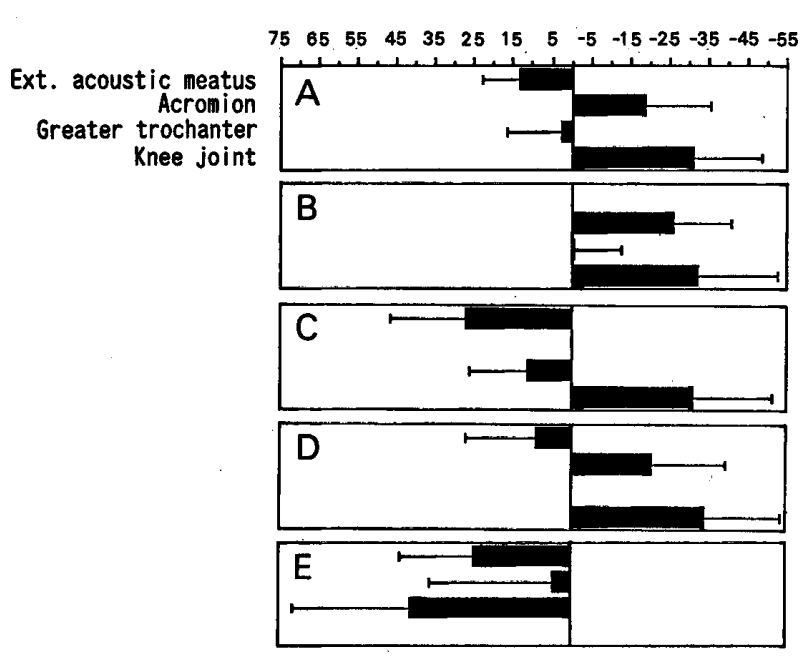

Fig. 2. Differences between markers and lines of center of gravity (LCG) in postural adjustment. A vertical line at 0 is LCG. A: standing naturally with no intention of making adjustments. B: after adjusting the external acoustic meatus to LCG. C: after adjusting the acromion. D: after adjusting the geater trochanter. Plus means that the marker is before LCG and minus means behind it. The unit of length is the millimeter. $\mathrm{n}=11$. tended to have their shoulders bent forward and knees over-extended. The position of the center of gravity was more anterior than usual ${ }^{4,5)}$. There were slight positive correlations between head and shoulder (coefficient of correlation 0.316), and between shoulder and hip (0.387).

The result of adjusting the markers to LCG was shown in Fig. 2. When subjects moved their heads backward to adjust the LCG, their shoulders also moved with it, but the positions of the hip and knee were the same as before moving (Fig. 2 B, the probabilties of hip and knee were $0.401,0.846$ respectively). Also, the position of the knee after having adjusted shoulders (C), and/or hips (D) were the same as before movement. As a result, we can consider the knee to be very stable. The stability of the knee was proven by the fact that during the process of adjusting the knee, all of body parts were changed dramatically $(\mathrm{E})$. The shifts of body parts during adjustment of the hip weren't so large. One of reasons may be that the deviation of the hip from LCG was small. So we normalized the length of shift, i.e. shifting lengths of the other markers were divided by the length of movement of maker adjusted. The normalized values (shift rates) were summarized in Table 2. The nearer the body part was to the marker adjusted,

Table 2. Normalized difference (rate of shift) between markers and the line of the center of gravity (LCG)

\begin{tabular}{|c|c|c|c|c|}
\hline & $\begin{array}{c}\text { Ext. acoustic } \\
\text { meatus }\end{array}$ & Acromion & $\begin{array}{l}\text { Greater } \\
\text { trochanter }\end{array}$ & $\begin{array}{l}\text { Knee } \\
\text { joint }\end{array}$ \\
\hline \multicolumn{5}{|c|}{ Ext. acoustic meatus } \\
\hline Average & -1.000 & -1.059 & -0.766 & -0.323 \\
\hline SD & 0.000 & 1.794 & 1.406 & 0.669 \\
\hline Acromion & 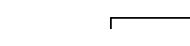 & $\longrightarrow$ & & \\
\hline Average & 0.929 & 1.000 & -0.707 & -0.071 \\
\hline SD & 0.750 & 0.000 & 0.879 & 0.606 \\
\hline \multicolumn{5}{|c|}{ Greater trochanter } \\
\hline Average & -2.224 & -0.306 & -1.000 & -0.304 \\
\hline SD & 2.104 & 3.932 & 0.000 & 0.675 \\
\hline Knee joint & & & - & $\longrightarrow$ \\
\hline Average & -0.449 & -0.838 & -1.454 & 1.000 \\
\hline $\mathrm{SD}$ & 1.015 & 0.829 & 0.661 & 0.000 \\
\hline
\end{tabular}

The rate of shift was calculated by means of dividing the differences between markers and LCG by the difference between markers adjusted to LCG. Plus means forward shift and minus backward shift. * indicates a significant difference in ANOVA $(\mathrm{P}<0.01)$. 
the more it was influenced. For example, when shoulder shifted forward (18.7 $\mathrm{mm}$ from Table 1), the shift rate of the head was 0.929 . In short, if the shoulder shifts forward to a certain point, the head will move forward to a distance 0.929 longer than that point. To take another example, if the knee shifted forward to a certain point, the hip moved backward 1.454 farther than that point. The results of statistical analysis with ANOVA indicate that there were significant differences only between head and shoulder during shoulder adjustment, and between the hip and knee during knee adjustment. Both the head and the hip were above the part of body adjusted. The body alignment was well controlled both during head and knee adjustment. In general, there were lots of differences between subjects, as indicated by a large SD.

\section{DISCUSSION}

Subjects that participated in this study made shoulder bend and the position of center of gravity was more anterior with respect to the lateral malleolus than is usually the case ${ }^{4}$, i.e. they had forward inclined posture. The position of the center of gravity in the body was similar to that of previous reports ${ }^{3) 6}$ ). We don't know whether or not the numerical values obtained in this study are normal. The subjects in this study were researchers (11) and students (4). The tendency of their posture may be related to their life-styles. Many young men today used to have bending posture, for example, working for an entrance, playing a TV game, operating a computer and so on. The references cited are very old (1950s 1960s), which may account for differences between them and the results of this study.

In this study, there was a slight positive correlation between the position of the head and shoulder, as well as that of the shoulder and hip. We also reported $^{3)}$ that the correlation of head to shoulder is strongly positive in young subjects (mean age 20.3 \pm 1.2 years) and shoulder to hip was slightly positive. Elderly subjects (mean age $75.5 \pm 4.9$ years) in the report had the same positive correlation of head to acromion but negative correlation of shoulder to hip. Accordingly, it is believed that the body alignment to LCG changes with age. The body alignment of subjects in this study seems to be included in young.
The experiment of postural adjustment revealed that the lower extremity, including greater trochanter and knee joint are very stable (Fig. 2B, C, D). This has been proven by the fact that when the stability of lower extremities were broken, the alignment of upper body part changed on a large scale (2E). It is generally believed that the stability of posture is kept by hip control. The greater trochanter is positioned near the body's center of gravity. So, we can presume that hip movement by ankle rotation is effective at controlling the center of body mass. Kuo and Zajac ${ }^{7)}$ also proposed the same idea. We cannot emphasize enough the importance of this concept to physical training aimed at postural correction.

The ability of postural adjustment can be seen by shift rates (Table 2). The shift rates of body were larger as near as to the part adjusted. When adjusting the shoulder to LCG, head moved with it in the same direction and when adjusting knee, hip moved with it in the opposite direction. Again, these parts were above the part adjusted. Consequently, it was suggested that the local center of gravity of the body parts was decided between neighboring parts. Whole center of gravity was made by putting together the local center of gravities, therefore the body alignment also was decided by the position of neighboring parts.

\section{CONCLUSION}

The center of gravity was found to be positioned more anteriorly than is usually believed to be the case. The position of the head was before LCG (line of center of gravity) and both shoulder and knee were behind it. Body alignment differed from so called "good posture".

The knee was stable at adjusting the other parts of body. The position of the hip was strongly influenced by that of knee. The stability of the knee is important for controlling the body's center of gravity.

\section{Acknowledgements}

The present study was supported by the help of researchers and students in Tsukuba Technical College. 


\section{REFERENCES}

1) Brunnstrom S: Center of gravity line in relation to ankle joint in erect standing. The Physical Therapy Review 34: 104-115, 1954.

2) Suzuki S: Measurement and classification of posture in Japanease people-on the aging effect-. Nippon Seikeigekagakkaishi 52: 471-492, 1978.

3) Takahashi K, et al: Standing alignment of the old people. Journal of Ibaragiken Physical Therapy 6: 1997 (In press).

4) Nakamura R, Saito S: Basic Kinesiology 4th ed,
Tokyo Ishiyaku Publisher, 1992, pp 289-303.

5) Harada T, et al: Position of line of gravity on standing posture. Jpn J Hum Posture 10:113-118, 1990.

6) Inoue $\mathrm{M}$ : On the relation of body alignment to a line of center of gravity, Graduation thesis, College of Medical Technology, Hokkaido University 8: 9-13, 1994.

7) Kuo AD, Zajac FE: Human standing posture: Multijoint movement strategies based on biomechanical constraints, Progress in Brain Research 97: 349-358, 1993. 